\title{
High temperature x-ray scattering studies of atomic layer deposited IrO2
}

\section{Heikkilä, Mikko J.}

2020-04-01

Heikkilä, M J , Hämäläinen , J , Puukilainen, E , Leskelä , M \& Ritala , M 2020 , ' High temperature $\mathrm{x}$-ray scattering studies of atomic layer deposited IrO2 ' , Journal of Applied Crystallography , vol. 53 , pp. 369-380 . https://doi.org/10.1107/S1600576720001053

http://hdl.handle.net/10138/314719

https://doi.org/10.1107/S1600576720001053

publishedVersion

Downloaded from Helda, University of Helsinki institutional repository.

This is an electronic reprint of the original article.

This reprint may differ from the original in pagination and typographic detail.

Please cite the original version. 


\section{High-temperature $X$-ray scattering studies of atomic layer deposited $\mathrm{IrO}_{2}$}

\section{Mikko J. Heikkilä, Jani Hämäläinen, Esa Puukilainen, Markku Leskelä and Mikko Ritala}

J. Appl. Cryst. (2020). 53, 369-380

\section{IU IUCr Journals CRYSTALLOGRAPHY JOURNALS ONLINE}

Copyright (C) International Union of Crystallography

Author(s) of this article may load this reprint on their own web site or institutional repository provided that this cover page is retained. Republication of this article or its storage in electronic databases other than as specified above is not permitted without prior permission in writing from the IUCr.

For further information see https://journals.iucr.org/services/authorrights.html 
JOURNAL OF

APPLIED

CRYSTALLOGRAPHY

ISSN 1600-5767

Received 3 May 2019

Accepted 26 January 2020

Edited by D. Pandey, Indian Institute of Technology (Banaras Hindu University), Varanasi, India

₹ Current affiliation: Picosun Oy, Masalantie 365, Masala 02430, Finland.

$\S$ Current affiliation: Vauhti Speed Oy,

Pamilonkatu 9, Joensuu 80100, Finland.

Keywords: $\mathrm{IrO}_{2}$; atomic layer deposition; ALD; high-temperature X-ray diffraction; HTXRD; high-temperature X-ray reflectivity; HTXRR.

Supporting information: this article has supporting information at journals.iucr.org/j

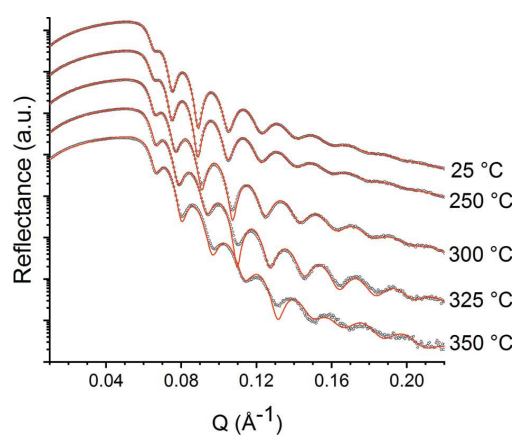

(C) 2020 International Union of Crystallography

\section{High-temperature $\mathrm{X}$-ray scattering studies of atomic layer deposited $\mathrm{IrO}_{2}$}

\author{
Mikko J. Heikkilä,* Jani Hämäläinen,‡ Esa Puukilainen,§ Markku Leskelä and Mikko \\ Ritala
}

Department of Chemistry, University of Helsinki, PO Box 55 (A. I. Virtasen aukio 1), University of Helsinki 00014 , Finland. ${ }^{*}$ Correspondence e-mail: mikko.j.heikkila@helsinki.fi

$\mathrm{IrO}_{2}$ is an important material in numerous applications ranging from catalysis to the microelectronics industry, but despite this its behaviour upon annealing under different conditions has not yet been thoroughly studied. This work provides a detailed investigation of the annealing of $\mathrm{IrO}_{2}$ thin films using in situ high-temperature X-ray diffraction and X-ray reflectivity (HTXRR) measurements from room temperature up to $1000^{\circ} \mathrm{C}$ in oxygen, nitrogen, forming gas and vacuum. Complementary ex situ scanning electron microscopy and atomic force microscopy measurements were conducted. The combined data show the dependencies of crystalline properties and surface morphology on the annealing temperature and atmosphere. The reduction of $\mathrm{IrO}_{2}$ to $\mathrm{Ir}$ takes place at a temperature as low as $150^{\circ} \mathrm{C}$ in forming gas, but in oxygen $\mathrm{IrO}_{2}$ is stable up to $800^{\circ} \mathrm{C}$ and evaporates as a volatile oxide at higher temperatures. The $\mathrm{IrO}_{2}$ crystallite size remains constant in oxygen up to $400^{\circ} \mathrm{C}$ and increases above that, while in the more reducing atmospheres the Ir crystallites grow continuously above the phase-change temperature. The role of HTXRR in the analysis is shown to be important since its high sensitivity allows one to observe changes taking place in the film at temperatures much below the phase change.

\section{Introduction}

Iridium oxide has found use in a surprisingly wide variety of applications, despite the cost and rarity of the raw material. The earliest studies of $\mathrm{IrO}_{2}$ were conducted by Claus as early as 1860 (Claus, 1860) and further by Wöhler and Witzmann in 1908 (Wöhler \& Witzmann, 1908), but broader interest towards the material arose in the mid-1960s when dimensionally stable anodes were introduced for the chlor-alkali industry (Hackwood et al., 1982; Trasatti, 2000). New applications were found in the 1980s when electrochromism and applicability for water electrolysis were discovered (Hackwood et al., 1982). Today, the field of possible applications has diversified even further, ranging from the still ongoing electrochromic studies (Wen et al., 2014) and water electrolysis (Rasten et al., 2003; Yagi et al., 2005; Hou et al., 2006; Carmo et al., 2013; Bernicke et al., 2015; Abbott et al., 2016; da Silva et al., 2017) to unitized regenerative fuel cells (Pettersson et al., 2006; Antolini, 2014), pH sensors (Huang et al., 2011) and biosensors (Shim et al., 2012), and, in medicine, cardiovascular stents (O'Brien \& Carroll, 2009) and neural stimulation and detection (Cogan, 2008).

Many of the aforementioned applications utilize $\mathrm{IrO}_{2}$ as particles or as thick and very rough films. The field that probably places the largest demands on high-quality thin films is microelectronics. $\mathrm{IrO}_{2}$ has been explored most often as the top (Park et al., 2005) or bottom electrode, e.g. in ferroelectric 
memories, multiferroics or microelectromechanical systems devices (Lee et al., 1999; Pinnow et al., 2001, 2002; Gong et al., 2013; Tomczyk et al., 2017; Potrepka et al., 2017; Okuyama, 2016), since it works as a diffusion barrier, has good phase stability at high temperatures under oxidizing conditions and is lattice matching with many ferroelectric materials, showing good structural and chemical compatibility. $\mathrm{IrO}_{2}$ is also very conducting, its bulk resistivity being $35-60 \mu \Omega \mathrm{cm}$. Furthermore, it has superior fatigue properties (Okuyama, 2016; Tomczyk et al., 2017) and even radiation hardness (Brewer et al., 2016) over commonly used Pt electrodes.

$\mathrm{IrO}_{2}$ has been synthesized using a wide selection of methods. Thermal decomposition has been widely used (Jang \& Rajeshwar, 1987; Hou et al., 2006), as has reactive sputtering (Hackwood et al., 1982; Sanjinés et al., 1989; Lee et al., 1999; Pinnow et al., 2001, 2002; Cogan, 2008; Kim, Kwon, Kwak \& Kang, 2008). Anodization of an Ir film (Cogan, 2008) and thermal oxidation of metallic iridium (Bayer \& Wiedemann, 1975; Chalamala et al., 1999, 2000) have been in use for a long period of time. Furthermore, $\mathrm{IrO}_{2}$ thin films are also deposited hydrothermally (da Silva et al., 2017) using the Adams fusion method (Rasten et al., 2003; Abbott et al., 2016), spray pyrolysis (Patil et al., 2003), electro-deposition (Yagi et al., 2005), sol-gel methods (Bernicke et al., 2015), pulsed-laser deposition (Gong et al., 2009; Hou et al., 2017), laser ablation (Wang et al., 2006; Gong et al., 2013), chemical vapour deposition (CVD) (Liao et al., 2001; Jürgensen et al., 2017) and atomic layer deposition (ALD) (Hämäläinen et al., 2008, 2014). Among the various thin-film deposition methods, ALD offers unsurpassed conformality and thickness uniformity properties, making it the method of choice for coating highly complex shapes (Ritala \& Niinistö, 2009; George, 2010; Leskelä et al., 2014).

Although the stability and microstructure of $\mathrm{IrO}_{2}$ are important e.g. in catalytic and oxygen evolution/reduction applications, they are also critical in microelectronics and integration into thin-film devices. While many methods have been used to deposit $\mathrm{IrO}_{2}$, there are surprisingly few detailed studies of how $\mathrm{IrO}_{2}$ behaves during post-deposition annealing. The most often used method for analysis is X-ray diffraction (XRD) (Jang \& Rajeshwar, 1987; Pinnow et al., 2001, 2002; Sanjinés et al., 1989; Kim, Shim et al., 2008; Bayer \& Wiedemann, 1975; Chalamala et al., 1999, 2000; Gong et al., 2009; Chen et al., 1997). Pinnow et al. (2001, 2002) even used XRD for stress analysis of an $\mathrm{IrO}_{2}$ film as a function of temperature. Thermogravimetry was used in some early studies (Hackwood et al., 1982; Jang \& Rajeshwar, 1987; Bayer \& Wiedemann, 1975), as was calorimetry (Jang \& Rajeshwar, 1987). Liao et al. (1997) used Raman spectroscopy, X-ray photoelectron spectroscopy (XPS) was used in a couple of studies (Sanjinés et al., 1989; Peuckert, 1984), and gases evolved during annealing have been analysed a few times (Hackwood et al., 1982; Pinnow et al., 2002; Chalamala et al., 2000). A change in film resistivity during annealing was studied by Sanjinés et al. (1989). While detailed experiments on thermal behaviour were conducted as early as the 1980 s, the films were often at least partially hydrated.
The aim of the present study was to perform a detailed hightemperature X-ray scattering study on atomic layer deposited $\mathrm{IrO}_{2}$ thin films that were annealed in different atmospheres: $\mathrm{O}_{2}, \mathrm{~N}_{2}$, forming gas $\left(5 \% \mathrm{H}_{2}\right.$ in $\left.\mathrm{N}_{2}\right)$ and vacuum. The changes in unit-cell parameters as determined by high-temperature X-ray diffraction (HTXRD) are presented, as well as information on the atmosphere-dependant decomposition into Ir. Changes in film roughness and surface morphology were followed using high-temperature X-ray reflectivity (HTXRR), atomic force microscopy (AFM) and field emission scanning electron microscopy (FESEM). The phase-change behaviour is discussed and the benefits of HTXRR in detecting changes in the film before actual phase changes occur are emphasized.

\section{Experimental}

Iridium oxide thin films were deposited from $\operatorname{Ir}(\mathrm{acac})_{3}(\mathrm{acac}=$ acetylacetonate) and ozone at $185^{\circ} \mathrm{C}$ in a hot-wall flow-type F-120 ALD reactor using a process developed by Hämäläinen et al. (2008). The reactor was operated under a nitrogen pressure of about $10 \mathrm{mbar}(1 \mathrm{bar}=100000 \mathrm{~Pa})$. Nitrogen (99.9995\%) was produced with a NITROX UHPN 3000 nitrogen generator and used as a carrier and purging gas. Silicon (100) was used as a substrate. Before loading into the reactor, the substrates were rinsed with ethanol and blown dry with nitrogen to remove dust particles. $\operatorname{Ir}(\text { acac })_{3}(99.9 \%$, ABCR) was sublimed from an open boat held inside the reactor at $155^{\circ} \mathrm{C}$. Ozone was produced with a Wedeco Ozomatic Modular $4 \mathrm{HC}$ ozone generator from oxygen (99.999\%, Linde Gas) and pulsed into the reactor through a needle valve and a solenoid valve from the main ozone flow line. The estimated ozone concentration output of the generator was about $100 \mathrm{~g} \mathrm{~N}^{-1} \mathrm{~m}^{-3}$. A total of 1000 ALD cycles were applied in the process, where the pulse and purge times for both precursors were $1 \mathrm{~s}$ each, producing films with a thickness of $340 \AA$.

Film crystallinity and phase structure were determined with a PANalytical X'Pert Pro MPD diffractometer using $\mathrm{Cu} K \alpha$ radiation. High-temperature measurements were conducted in an Anton Paar HTK1200N oven. Oxygen (99.9999\%), nitrogen $(99.999 \%$, further purified with Entegris 35KF-I-4R inert gas purifier) and forming gas $\left(5 \% \mathrm{H}_{2}\right.$ in $\left.\mathrm{N}_{2}\right)$ were used at 10 50 mbar above ambient pressure (due to the check valve at the furnace outlet) for annealing in gaseous atmospheres, while vacuum measurements were conducted at $<10^{-3}$ mbar. The temperature was raised at a rate of $15^{\circ} \mathrm{C} \mathrm{min}^{-1}$ and a $2 \mathrm{~min}$ waiting period preceded each $30 \mathrm{~min}$ measurement done at constant temperature, giving an effective heating rate of approximately $1.2 \mathrm{C} \mathrm{min}^{-1}$. Grazing-incidence X-ray diffraction (GIXRD) measurements were done using a multilayer mirror, a $0.18^{\circ}$ parallel-plate collimator and a PIXcel detector. The angle of incidence was $1^{\circ}$ for all GIXRD measurements. The same setup with an additional $0.1 \mathrm{~mm}$ parallel-plate collimator slit was used for the HTXRR measurements. Before the X-ray reflectivity (XRR) measurements, the correct sample height position and omega offset were determined for each temperature. The $M A U D$ software package 
was used for Rietveld refinement of the diffractograms (Lutterotti et al., 2004). Fitting to the XRR data was done using REFLEX35 (Vignaud \& Gibaud, 2019) and MOTOFIT (Nelson, 2006), and on a few occasions STOCHFIT was used to evaluate the structure (Danauskas et al., 2008).

The XRR fitting procedure consisted of several steps. The whole film thickness was first modelled with ten slices of variable density, and in each slice the roughness was limited to one half of the thickness. The layers were thinner closer to the interface (in order to detect better any abrupt changes taking place there) and at the surface (in case the Nevot-Croce roughness model was not adequate for modelling the surface roughness, which might not be Gaussian due to the changes taking place while annealing). Importantly, the effect of the sample size and incident-beam size were taken into account in REFLEX35, as the sample length was below $18 \mathrm{~mm}$ due to the furnace size.

The XRR data of the as-deposited layers were fitted using as free parameters the surface-layer thickness and roughness, the buffer $\mathrm{SiO}_{2}$ layer thickness and roughness, and all the densities. All the other values were kept constant. The data were first fitted using a genetic algorithm in MOTOFIT or Nelder-Mead minimization in REFLEX35, in order to approach the global minimum of the fit. After both methods gave close-to-equal results, the fit was improved in REFLEX35 using the interior-point algorithm (Vignaud \& Gibaud, 2019) to reach the absolute local minimum. The densities are scattering length densities (SLDs) and thus not dependent on the stoichiometry of the film. After a satisfactory fit had been reached, the same values were used as starting values for the next temperature data set, unless there were large differences, in which case global optimizations were again tried at first.

The film morphology was studied with a Hitachi S-4800 field emission scanning electron microscope. For AFM studies a Veeco Instruments Multimode V with Nanoscope V controller was used. Samples were measured in tapping mode in air using a phosphorus-doped silicon probe (RTESP) supplied by Veeco Instruments. Several scans were performed on different parts of the samples to check the uniformity of the surface. Final images were taken from a scanning area of $2 \times 2 \mu \mathrm{m}$ with a scanning frequency of $0.5 \mathrm{~Hz}$, and no image processing except flattening was performed. Roughness values $k$ were calculated as root-mean-square values $\left(R_{q}\right)$.

\section{Results and discussion}

\subsection{X-ray scattering}

3.1.1. Annealing in an oxygen atmosphere. Rietveld refinement of the GIXRD data of the as-deposited film is depicted in Fig. 1(a). No other phases than tetragonal $\mathrm{IrO}_{2}$ are present (Bolzan et al., 1997). Since the widths of the first two reflections in the $\mathrm{IrO}_{2}$ diffractograms were very different $\left[\mathrm{FWHM}=1.37^{\circ} 2 \theta\right.$ for the (110) reflection at $28.0^{\circ} 2 \theta$, and $0.65^{\circ} 2 \theta$ for the $(101)$ reflection at $34.9^{\circ} 2 \theta$ ], the crystallite size and shape were considered to be anisotropic and refinements were thus made using the Popa rules for anisotropic crystallite size (Popa, 1998). Similar XRD patterns were obtained by Abbott et al. (2016) in their powder synthesis and, on the basis of high-resolution transmission electron microscopy, this was related to preferred crystallite growth in the [001] and [112] directions. Since the intensity ratios differed from the standard ratios and because no real texture information was available, an arbitrary texture model was used to correct the intensity differences. The same methodology was used to refine the results acquired in nitrogen, vacuum and forming gas. The $R_{\mathrm{wp}}$ values remain quite high (almost 0.15 at worst) in all refinements due to high noise related to the fast acquisition. However, this was considered acceptable for the level of detail studied here.

GIXRD measurements of an $\mathrm{IrO}_{2}$ film heated in oxygen are depicted in Fig. 1(b). The tetragonal $\mathrm{IrO}_{2}$ phase remains up to $800^{\circ} \mathrm{C}$, and above that temperature $\mathrm{IrO}_{2}$ is barely observed in the diffractograms. No new phases appear upon the disappearance of $\mathrm{IrO}_{2}$. The broad bump observed at higher temperatures around $55^{\circ} 2 \theta$ originates from the Si substrate.

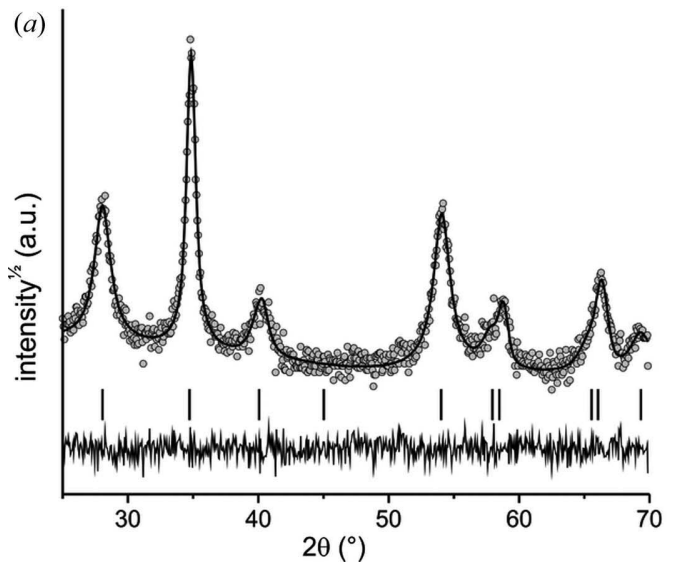

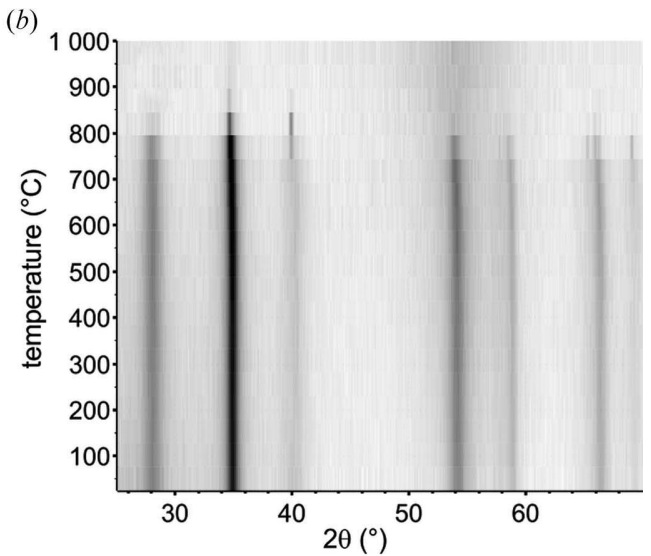

Figure 1

(a) Rietveld refinement of the GIXRD data of the as-deposited $\mathrm{IrO}_{2}$ film. The grey circles represent the measured data and the solid line the simulation. Vertical bars show the locations of the reflections in the reference data, and the difference between the measured and simulated data is shown at the bottom. (b) High-temperature GIXRD data of an $\mathrm{IrO}_{2}$ film annealed in an oxygen atmosphere. 
Our results are well in line with several other studies performed in either oxygen or air, where $\mathrm{IrO}_{2}$ has been observed to be stable up to $750-850^{\circ} \mathrm{C}$ (Lee et al., 1999; Chen et al., 1997; Cha \& Lee, 1999; Zhang et al., 2005; Kim, Kwon, Jeong et al., 2008; Gong et al., 2009; Pinnow et al., 2002). Similarly to our case, Chalamala et al. $(1999,2000)$ noted that, after heating their pulsed-laser-deposited films to $900^{\circ} \mathrm{C}$, there was no sign of Ir on the surface according to XPS, and similar findings of $\mathrm{IrO}_{2}$ nanowires being vaporized have been reported by Zhang et al. (2005). This is in contrast to the fact that bulk $\mathrm{IrO}_{2}$ should be stable up to $1100^{\circ} \mathrm{C}$ before decomposing (Rumble, 2018). Some authors suggest that the disappearance of the film is due to the formation of volatile $\mathrm{IrO}_{x}$ species (Chalamala et al., 1999; Kim, Kwon, Jeong et al., 2008), and Shim et al. (2012) even used this to grow $\mathrm{IrO}_{2}$ films by evaporating $\mathrm{IrO}_{2}$ at $1000^{\circ} \mathrm{C}$ and condensing the vapours onto the substrate at $700^{\circ} \mathrm{C}$.

In contrast to the findings above, $\mathrm{IrO}_{2}$ has been observed to decompose to Ir at high temperatures - one group observed this at $850^{\circ} \mathrm{C}$ (Kim, Kwon, Jeong et al., 2008) and another at 1000-1050 $\mathrm{C}$ (Jang \& Rajeshwar, 1987). According to Sanjinés et al. (1989), sputter-deposited iridium oxide decomposes already at $400^{\circ} \mathrm{C}$, although this was probably a decomposition of a hydrated film into either $\mathrm{Ir}$ or $\mathrm{IrO}_{2}$, depending on the degree of hydration of the sample. This indicates that the decomposition of $\mathrm{IrO}_{2}$ has a dependence on temperature and the partial pressure of oxygen during annealing, as explained by Cha \& Lee (1999) and discussed later in Section 3.1.3.

The unit-cell parameters were determined using Rietveld refinement and are depicted in Fig. 2. Horizontal arrows point to the literature values reported by Bolzan et al. (1997). While the $a$ axis is quite close to the literature value of $4.5051 \AA$, the $c$ axis is slightly shorter ( $3.1584 \AA$ in the literature). The unit-

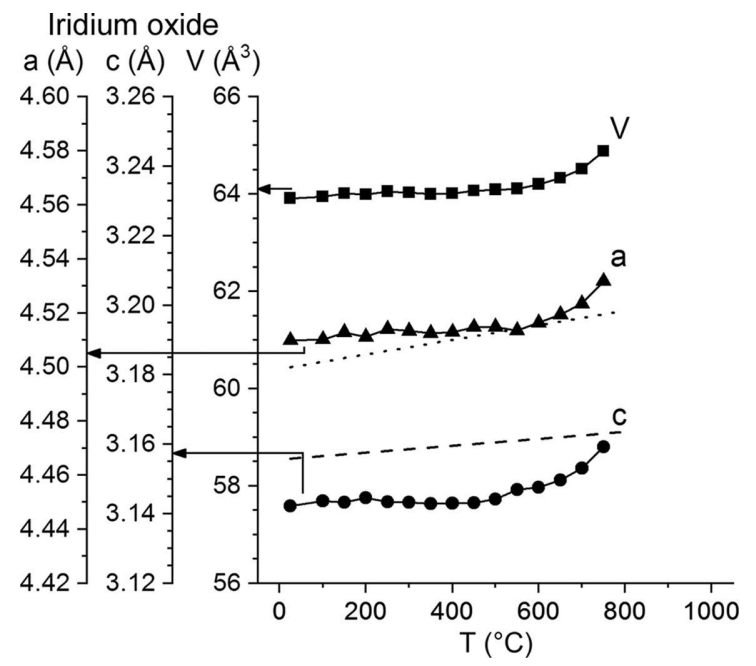

Figure 2

Rietveld-refined unit-cell parameters as a function of temperature for an $\mathrm{IrO}_{2}$ film annealed in oxygen. The three $y$ axes on the left-hand side are for the $a$ axis, $c$ axis and volume of the $\mathrm{IrO}_{2}$ unit cell. The horizontal arrows point to the axes at the positions of the literature values of the room-temperature unit-cell dimensions. The averages of literature values are shown as a dotted line for the $a$ axis and a dashed line for the $c$ axis. (Rao \& Iyengar, 1969; Bayer \& Wiedemann, 1975). cell parameters remain nearly constant up to $500^{\circ} \mathrm{C}$ with a tiny maximum for the $c$ axis at $200-250^{\circ} \mathrm{C}$. Above $500^{\circ} \mathrm{C}$, the unitcell parameters increase until the data are no longer refinable above $750^{\circ} \mathrm{C}$. This is quite different from the literature data shown in Fig. 2, where the averages of two powder sample measurement results by Rao \& Iyengar (1969) and Bayer \& Wiedemann (1975) are plotted as dotted ( $a$ axis) and dashed ( $c$ axis) lines. The room-temperature values are already different, and the slopes are different as well. This indicates that thermal expansion is restricted, probably due to the different thermal expansion coefficients between the silicon substrate and the $\mathrm{IrO}_{2}$ film. The faster expansion of the cell parameters above $600^{\circ} \mathrm{C}$ could be related to stress relaxation and recrystallization, as similar results were observed by Pinnow et al. (2001, 2002) with their sputtered films.

In addition to the HTXRD studies, XRR was measured as a function of temperature, and the results are shown in Fig. 3. As explained in the Experimental section, initial fits to these data were performed using a ten-slice model, but ultimately a twolayer model was enough to fit the data accurately (see Fig. S1 in the supporting information). A thin (16 $\AA$ ) layer with an SLD of $9.0 \times 10^{-5} \AA^{-2}$ was found next to the substrate, and this is thought to be a layer composed of $\mathrm{IrO}_{2}$ with a small amount of Ir, as the SLD value for bulk $\mathrm{IrO}_{2}$ is smaller, about $7.8 \times 10^{-5} \AA^{-2}$. The SLD of the rest of the film was $7.6 \times 10^{-5} \AA^{-2}$, close to the bulk value. A small amount of Ir at the interface is plausible when considering the original process paper by Hämäläinen et al. (2008). There, the $\mathrm{Ir} / \mathrm{O}$ ratio was constant at 1:2 when the deposition was done at $185^{\circ} \mathrm{C}$, while at a deposition temperature of $200^{\circ} \mathrm{C}$ the ratio was almost $1: 1$ at the substrate interface, suggesting partial reduction to metallic Ir at the beginning of the growth. Even though our film was deposited at $185^{\circ} \mathrm{C}$ where the stoichiometry should be 1:2, a layer of Ir a few nanometres thick at the interface would have been practically invisible to XRD or to

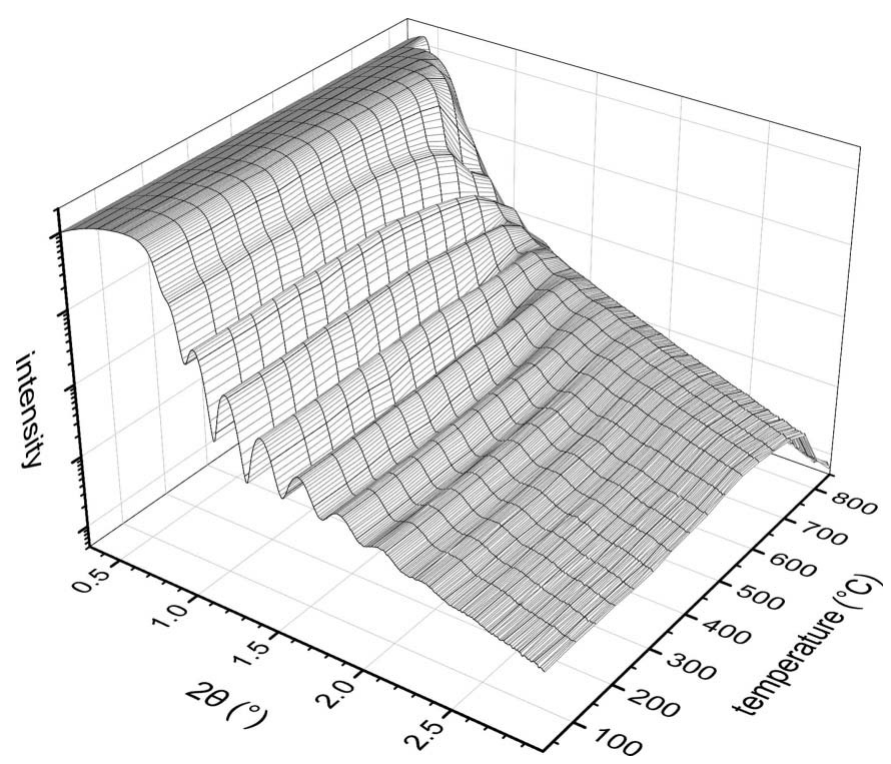

Figure 3

HTXRR measurements of an $\mathrm{IrO}_{2}$ film in an oxygen atmosphere. 
compositional analysis with elastic recoil detection analysis and might have been present in their study as well.

The acquired SLD, total thickness and surface roughness values are depicted as a function of temperature in Fig. 4(a)

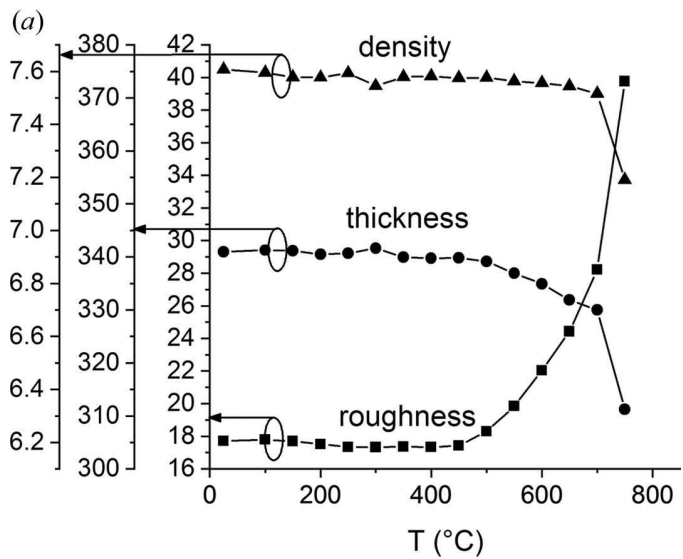

(b)

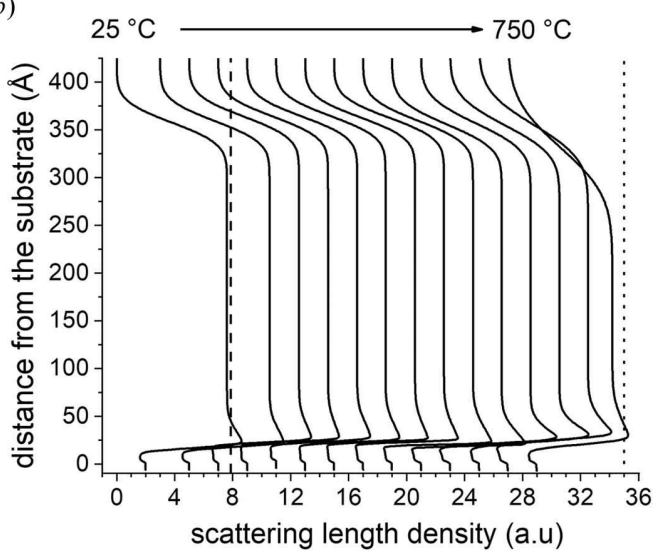

Figure 4

(a) $\mathrm{IrO}_{2} \mathrm{SLD}\left(\times 10^{-5} \AA^{-2}\right)$, total thickness $(\AA)$ and surface roughness $(\AA)$ of the oxygen-annealed film as a function of temperature. (b) SLD as a function of distance from the substrate at varying temperature. The curves are shifted horizontally for clarity by two SLD units for each $50^{\circ} \mathrm{C}$. The two vertical lines represent the SLDs of bulk $\mathrm{IrO}_{2}$ for the measurements conducted at $25^{\circ} \mathrm{C}$ (dashed) and $750^{\circ} \mathrm{C}$ (dotted). (fits to the data are shown in Fig. S1 in the supporting information). All the values remain quite constant up to $450^{\circ} \mathrm{C}$, and this is also seen in the shape of the SLD plot in Fig. 4(b). At $450^{\circ} \mathrm{C}$ the higher-density layer at the interface gets thinner and denser, probably due to coalescence of the remaining Ir. Although a pure Ir film starts to oxidize at $500^{\circ} \mathrm{C}$ according to our earlier study (Heikkilä et al., 2011), the diffusion-barrier properties of the deposited $\mathrm{IrO}_{2}$ seem to prohibit the Ir layer from oxidizing completely, even at higher temperatures.

At $500^{\circ} \mathrm{C}$ and higher temperatures the roughness begins to increase rapidly, most likely due to the crystal growth of the film as shown later in Section 3.1.5. As this temperature coincides with the onset of the increase in unit-cell parameters, the structure probably relaxes at that point. Even though macrostress was not found on the basis of the Rietveld refinement, the average microstrain decreases towards higher temperatures (see Section 3.1.5). The overall change in density is a combination of several effects, as the increase in unit-cell size should lead to a density decrease while the grain growth reduces the number of grain boundaries and thus densifies the film. Indeed, from $25^{\circ} \mathrm{C}$ to $700^{\circ} \mathrm{C}$ the values of bulk $\mathrm{IrO}_{2}$ film SLD and unit-cell volume both change about $1 \%$ in opposite directions, while simultaneously the total layer thickness decreases by $11 \AA$ (about $4 \%$ ), the densification of the Ir layer alone being $4 \AA$ (see Fig. S2 in the supporting information). It appears that the film gets thinner more than the density change would suggest, but the reason for this is unknown.

Above $650^{\circ} \mathrm{C}$, the density and thickness both decrease, most likely due to the onset of film decomposition as observed in diffraction data at higher temperatures, but also as crack formation in $750^{\circ} \mathrm{C}$ scanning electron microscopy images (see Section 3.1.6).

3.1.2. Annealing in a nitrogen atmosphere. High-temperature XRD results for an $\mathrm{IrO}_{2}$ film heated in a nitrogen atmosphere are depicted in Fig. 5. When the temperature reaches $\sim 650^{\circ} \mathrm{C}, \mathrm{IrO}_{2}$ begins to decompose to metallic iridium, and this transformation is completed at $750^{\circ} \mathrm{C}$. Ir then remains stable up to the highest studied temperature of $1000^{\circ} \mathrm{C}$.

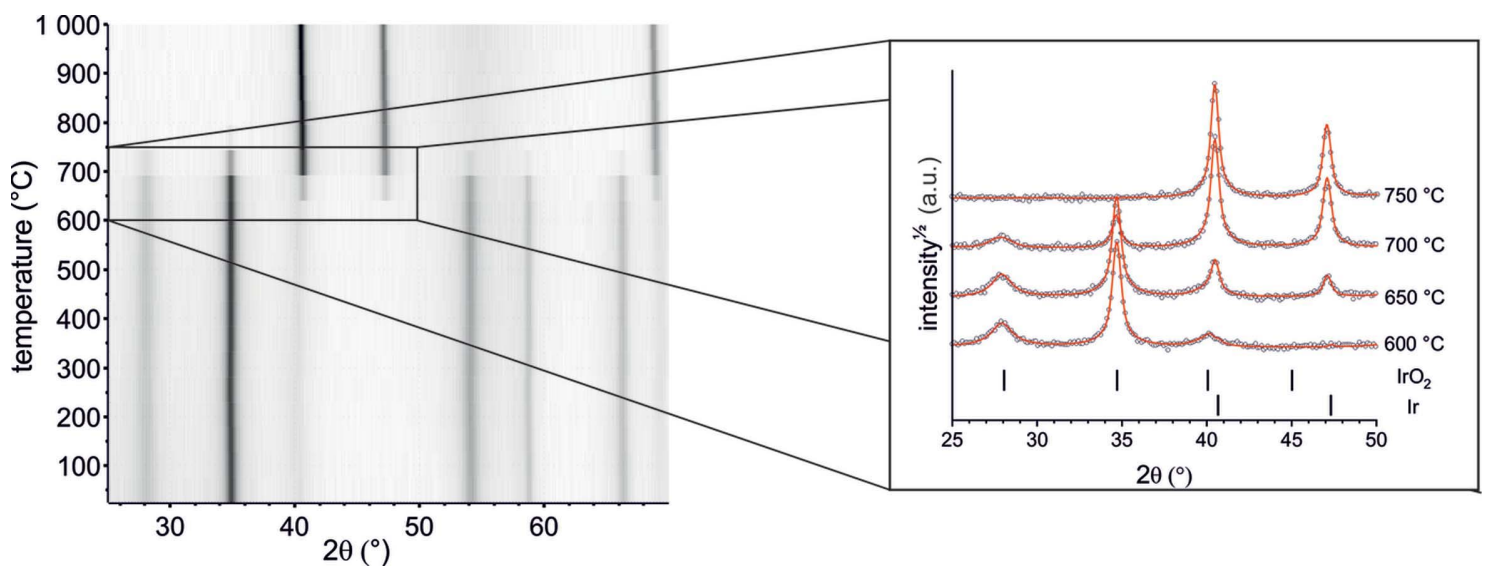

Figure 5

GIXRD measurements of an $\mathrm{IrO}_{2}$ film annealed in a nitrogen atmosphere. The enlarged region on the right-hand side depicts the diffractograms at temperatures where decomposition takes place; open circles are the measured data and red lines the Rietveld fits to the data. 
Our results agree well with the earlier studies. $\mathrm{IrO}_{2}$ films made by Kim, Shim et al. (2008) decomposed to Ir between $500-750^{\circ} \mathrm{C}$ in $\operatorname{argon}$, while Chen et al. (1997) noticed partial decomposition from $\mathrm{IrO}_{2}$ to $\mathrm{Ir}$ taking place at $700^{\circ} \mathrm{C}$ with their sputtered films. Zhang et al. (2005) observed their $\mathrm{IrO}_{2}$ nanowires starting to decompose to $\mathrm{Ir}$ at $700^{\circ} \mathrm{C}$ and no $\mathrm{IrO}_{2}$ was left at $800^{\circ} \mathrm{C}$. Slightly different results were obtained by Hackwood et al. (1982), who found their $\mathrm{IrO}_{2}$ films to be stable at $790^{\circ} \mathrm{C}$ in Ar. Sanjinés et al. (1989) observed a noticeable change in film resistivity below $300^{\circ} \mathrm{C}$ when the film was heated in $\mathrm{Ar}$, and the resistivity change was completed at $500^{\circ} \mathrm{C}$, but this was probably due to a gradual decomposition from hydrated $\mathrm{IrO}_{2}$, first to $\mathrm{IrO}_{2}$ and then to Ir. In the work by Choi et al. (2007), $\mathrm{IrO}_{2}$ nanodots embedded in an $\mathrm{SiO}_{2}$ film were found to be stable at $800^{\circ} \mathrm{C}$, which may be important when considering bottom electrode application where $\mathrm{IrO}_{2}$ is often covered by oxide layers.

The unit-cell parameters as a function of temperature are depicted in Fig. 6. While the parameters remained quite constant in oxygen (Fig. 2), in nitrogen there is a slight increase in the parameters up to $250^{\circ} \mathrm{C}$ that is much more obvious than during the $\mathrm{O}_{2}$ annealing. The reason for this is unclear, but as Sanjinés et al. (1989) observed a resistivity drop within a similar temperature range due to a partial loss of oxygen, this might also be the case here. On the other hand, this temperature range is just above the deposition temperature and might be additionally related to film relaxation. Above $250^{\circ} \mathrm{C}$ there is a small decrease in the unit-cell parameters, after which they stay constant until the decomposition into Ir takes place. On heating further, Ir shows a close-tolinear thermal expansion behaviour.

The effect of the heating rate was tested by measuring a constant $2^{\circ} 2 \theta$ window during heating (see Fig. S3 in the supporting information). One measurement took $1 \mathrm{~min}$, and

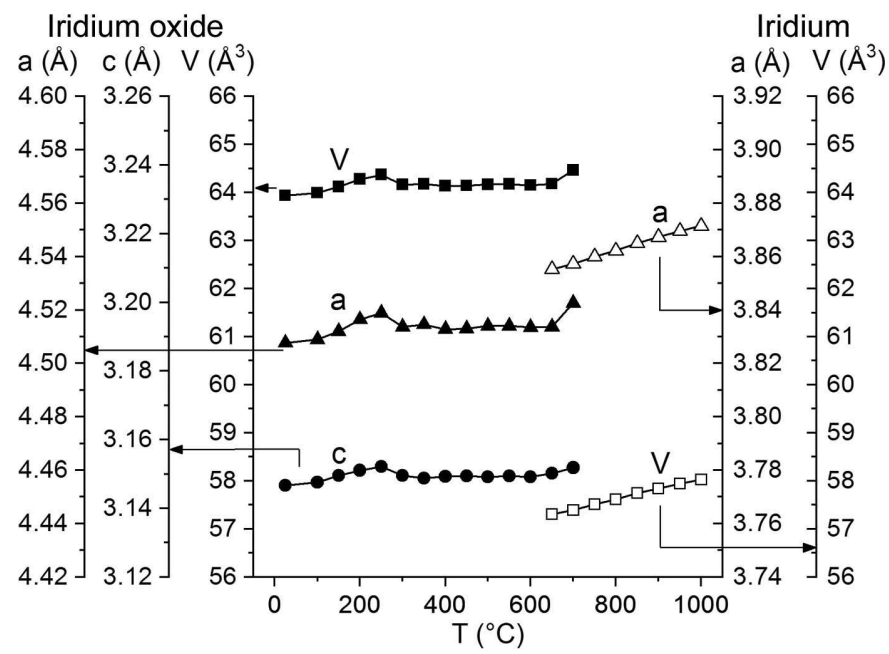

Figure 6

Rietveld-refined unit-cell parameters as a function of temperature for an $\mathrm{IrO}_{2}$ film annealed in nitrogen. The three $y$ axes on the left-hand side are for the $a$ axis, $c$ axis and volume of the $\mathrm{IrO}_{2}$ unit cell, and the two $y$ axes on the right-hand side are for the $a$ axis and volume of the Ir unit cell. The horizontal arrows point to the axes at the positions of the literature values of the room-temperature unit-cell dimensions. the heating rate was either 20 or $1^{\circ} \mathrm{C} \mathrm{min}{ }^{-1}$. At the higher heating rate the phase transformation seemed to occur at a temperature $25^{\circ} \mathrm{C}$ higher than with the slower heating. However, as the temperature increased by $20^{\circ} \mathrm{C}$ during each fast scan, there was also a rather large error in the temperature with the higher heating rate.

Fitting the XRD data was much more complicated than when the annealing was done in oxygen. Selected XRR curves, SLD profiles, thickness and surface roughness are depicted in Fig. 7 (all the fits are shown in Fig. S1 of the supporting information). There is practically no change between room temperature and the measurement done at $250^{\circ} \mathrm{C}$, but the

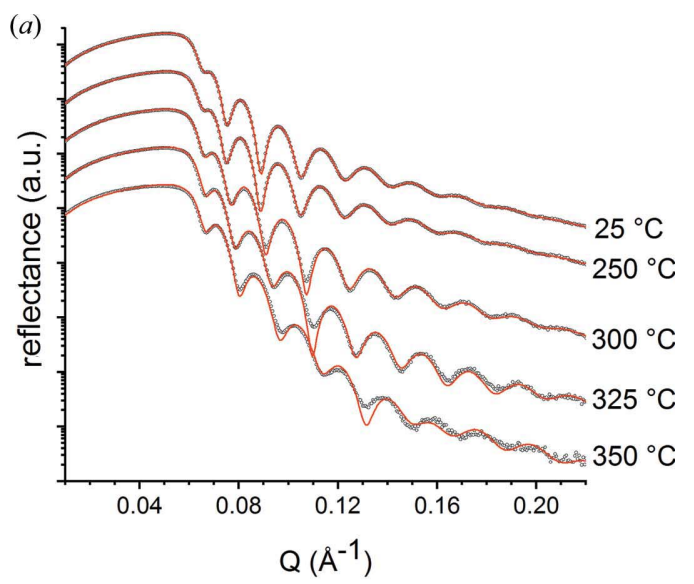

(b)
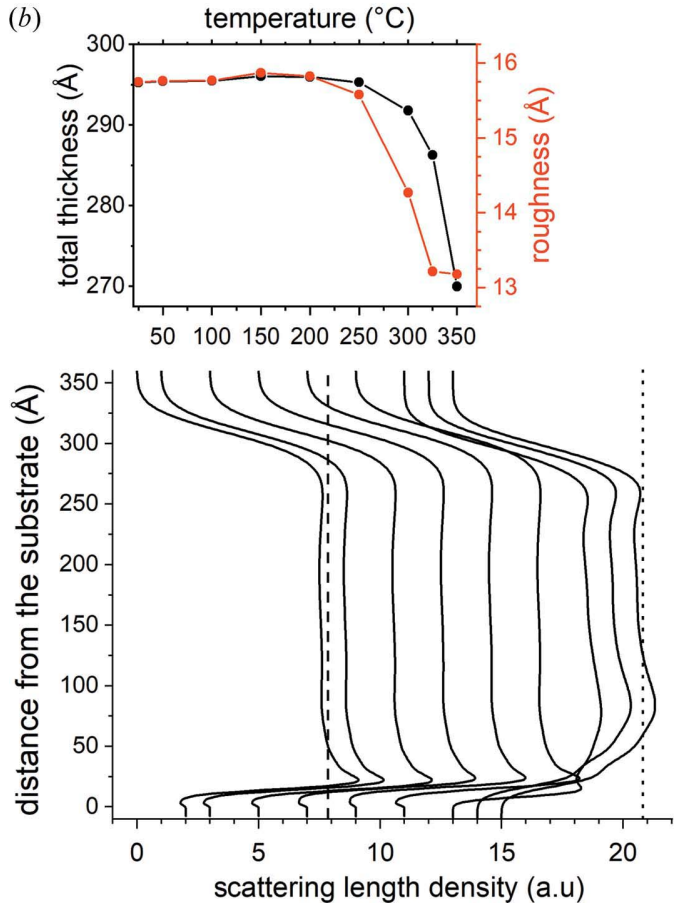

Figure 7

(a) Selected XRR curves and fits for the samples annealed in nitrogen. The curves are shifted vertically for clarity. (b) The upper plot shows the total thickness $(\AA)$ and the surface roughness $(\AA)$ of the annealed film as a function of temperature. SLD curves at the same temperatures are shown in the lower plot. The curves are shifted horizontally for clarity by two SLD units for each $50^{\circ} \mathrm{C}$. The two vertical lines represent the SLDs of bulk $\mathrm{IrO}_{2}$ for the measurements conducted at $25^{\circ} \mathrm{C}$ (dashed) and $750^{\circ} \mathrm{C}$ (dotted). 
reflectogram clearly changes at $300^{\circ} \mathrm{C}$ and even more so at higher temperatures. The fringe separation increase is obviously caused by the thickness of the film decreasing from 295 to $270 \AA$ between 250 and $350^{\circ} \mathrm{C}$, as shown in the upper panel of Fig. 7(b). The decay rate of the amplitude envelope is usually directly related to the increase in surface roughness, which implies that here the surface roughness decreases when the sample is heated above $300^{\circ} \mathrm{C}$, and according to the fit it decreases from 15.7 to $13.2 \AA$ [see Fig. 7(b)]. However, density gradients at the interfaces and within the film itself may cause changes in the amplitude as well. In this case it appears that there are large variations in the density, as the best fit to the $300^{\circ} \mathrm{C}$ data was obtained when there was a decrease in density close to the substrate interface, the native oxide was removed from the model and the Si substrate roughness was allowed to increase, as seen in the SLD plot of Fig. 7(b). The reason for this is not clear and would require more ex situ measurements like cross-section transmission electron microscopy. This trend continued up to $350^{\circ} \mathrm{C}$, while above that temperature the data could not be fitted with any reasonable model. Fig. 7(b) also shows the bulk $\mathrm{IrO}_{2}$ SLD value as a dotted line for the sample measured at $350^{\circ} \mathrm{C}$, and it is quite clear that the main part of the film is still $\mathrm{IrO}_{2}$, as observed in the HTXRD experiment (Fig. 5).

As part of the SLD curve reaches higher levels than the $\mathrm{IrO}_{2}$ bulk value, it is plausible that $\mathrm{IrO}_{2}$ already starts to reduce partially at this stage, even though there is no indication of this in the XRD. Since the SLD is still far below the bulk value for $\operatorname{Ir}\left(14.5 \times 10^{-5} \AA^{-2}\right)$, there are probably small Ir crystallites embedded in the $\mathrm{IrO}_{2}$ matrix, making it impossible to see them with XRD here. The partial reduction probably causes the thickness decrease as well.

There are multiple effects affecting the density. The release of oxygen will decrease the SLD of the material (even though the number of electrons is low compared with Ir), while at the same time thermal expansion will decrease the density as well. In addition, when $\mathrm{IrO}_{2}$ starts to reduce to $\mathrm{Ir}$, there are locally higher-SLD Ir parts, but the reduction may also produce voids or shrinkage in the film, again lowering the density. One should keep in mind that composing the model film from multiple slices of varying density has some drawbacks, since several different SLD profiles might give the same reflectivity curve because the phase information is lost in XRR measurements (van der Lee, 2000). However, it has been used successfully on many occasions (Sun et al., 2006; Danauskas et al., 2008; Mishra et al., 2012), and here several different solutions were evaluated until the chosen model gave the best fit while still being physically reasonable.

Interestingly, the temperature range of the first change in the reflectivity curves coincides with the small change found in the lattice parameters (Fig. 6) in the same temperature range, so some form of reconstruction of the film/substrate interface is probably taking place. Since the same was not observed in the HTXRR data from the $\mathrm{O}_{2}$-annealed sample, it is probably not related to stress relief or similar reasons but may relate to a possible loss of oxygen that would cause density differences within the film. Note that all the changes take place much below the phase-change temperature and do not seem to be related to changes in crystallinity (see Section 3.1.5). This emphasizes the efficiency of HTXRR in detecting minor changes in thin films during annealing, and similar results were also obtained in our earlier study related to the oxidation of noble metals (Heikkilä et al., 2011).

3.1.3. Annealing in a vacuum. Stability in a vacuum and at low oxygen partial pressures is important, especially when $\mathrm{IrO}_{2}$ is used as a bottom electrode, as the following layer is often deposited under such conditions. GIXRD measurements of an $\mathrm{IrO}_{2}$ film during annealing in a vacuum are shown in Fig. 8. The transformation to the Ir phase begins at $200^{\circ} \mathrm{C}$, much lower than was observed when annealing in a nitrogen atmosphere. $\mathrm{IrO}_{2}$ decomposition is complete at $250^{\circ} \mathrm{C}$. Poorly crystalline Ir forms first and larger crystallites start to grow above $500^{\circ} \mathrm{C}$.

Peuckert (1984) observed an oxidized Ir surface to decompose into elements in UHV at temperatures between 577 and $627^{\circ} \mathrm{C}$, and he noted that this was much higher than the temperature of $227^{\circ} \mathrm{C}$ observed with bulk $\mathrm{IrO}_{2}$. Sanjinés et al. (1989) found a significant decrease in resistivity around $200^{\circ} \mathrm{C}$, which is close to the temperature where we observed the phase change here. According to XPS studies, the O/Ir ratio

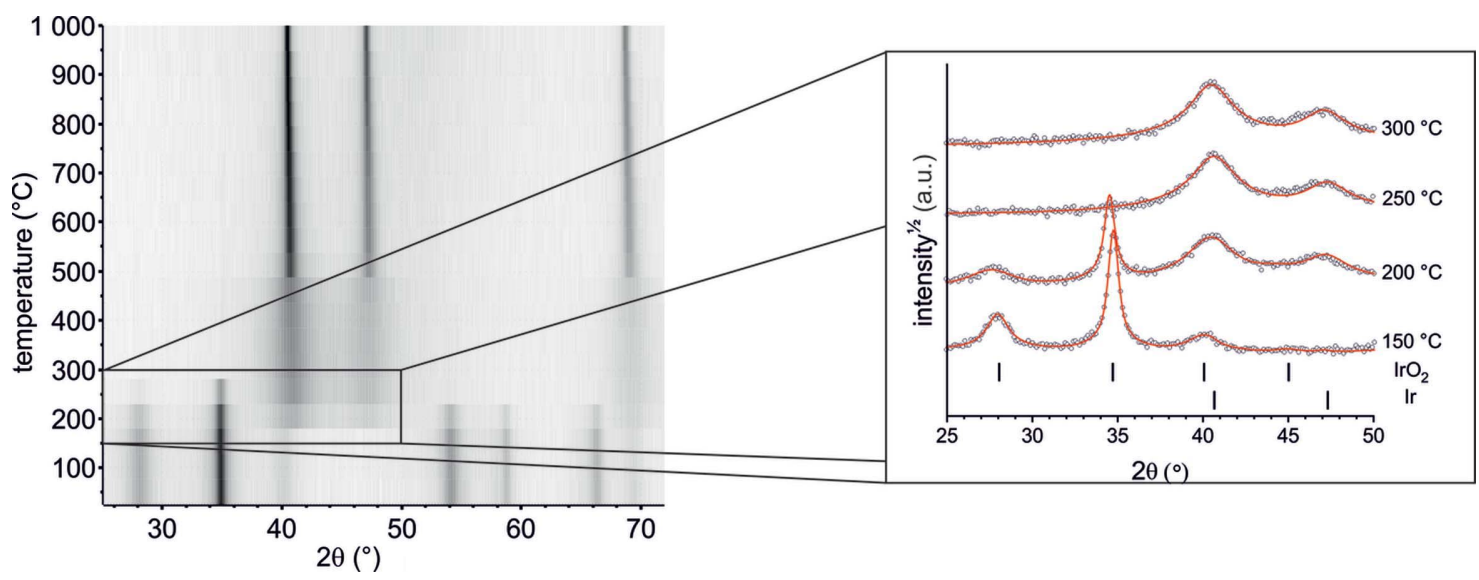

Figure 8

GIXRD measurements of an $\mathrm{IrO}_{2}$ film annealed in a vacuum. The enlarged region on the right-hand side depicts the diffractograms at temperatures where the decomposition takes place; open circles are the measured data and red lines the Rietveld fits to the data. 


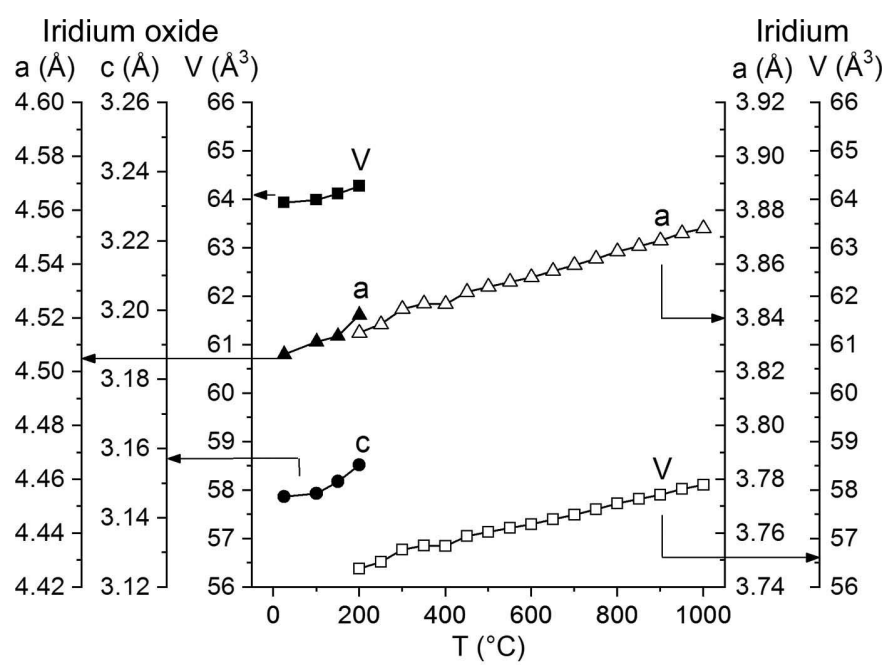

Figure 9

Rietveld-refined unit-cell parameters as a function of temperature for an $\mathrm{IrO}_{2}$ film annealed in a vacuum. The three $y$ axes on the left-hand side are for the $a$ axis, $c$ axis and volume of the $\mathrm{IrO}_{2}$ unit cell, and the two $y$ axes on the right-hand side are for the $a$ axis and volume of the Ir unit cell. The horizontal arrows point to the axes at the positions of the literature values of the room-temperature unit-cell dimensions.

was 0.7 between 200 and $400^{\circ} \mathrm{C}$, and thus a mixture of $\mathrm{IrO}_{2}$ clusters in Ir metal was thought to be present. Above $400^{\circ} \mathrm{C}$ the film was all metal with no oxygen detected. In their very interesting paper related to the deoxidation of a sputtered $\mathrm{IrO}_{2}$ film, Cha \& Lee (1999) used thermodynamics to calculate the relationship between the $\mathrm{O}_{2}$ partial pressure and temperature required for the $\mathrm{IrO}_{2}$ dissociation. According to their results, under the conditions of our experiments $\left(<10^{-3}\right.$ mbar $)$ the dissociation temperature would be 400 $500^{\circ} \mathrm{C}$, much higher than what we and some others have observed. Gong et al. (2013) have complemented the study of Cha and Lee, and they reported that their pulsed-laserdeposited $\mathrm{IrO}_{2}$ films were stable at a temperature as high as $800^{\circ} \mathrm{C}$ when the $\mathrm{O}_{2}$ partial pressure was 100 mbar, but the stability limit decreased to $300^{\circ} \mathrm{C}$ at a lower $\mathrm{O}_{2}$ partial pressure of $10^{-8}$ mbar. They noticed that the deposition method has an effect on the film stability but did not comment on the effect of film thickness, which will most likely affect the stability as well. They used $500 \mathrm{~nm}$ films in their study, while here the thickness is more than an order of magnitude lower, which might explain changes occurring at lower temperatures. Byun \& Lee (2004) conducted a similar experiment by annealing a $50 \mathrm{~nm}$ metal-oxide $\mathrm{CVD} \mathrm{IrO}_{2}$ film in a vacuum with different $\mathrm{O}_{2}$ partial pressures. Their results show that the $\mathrm{O}_{2}$ partial pressure needed to keep the films as $\mathrm{IrO}_{2}$ was several orders of magnitude higher than in the study by Gong et al. (2013), which means that for the same partial pressure the films would decompose at a lower temperature and the film thickness may indeed be an important parameter. Possible reasons for this are that there is less material to decompose, shorter diffusion lengths are needed for the oxygen to be removed, and the less developed crystallinity includes more defects through which the reduction can begin.

The refined unit-cell parameters are depicted in Fig. 9. When compared with the annealing in nitrogen, the increase in the unit-cell parameters is clearly faster up to decomposition at $200^{\circ} \mathrm{C}$. When the film was annealed in nitrogen, there was an increase in the unit-cell parameters up to $250^{\circ} \mathrm{C}$, but the unit-cell parameters stabilized after that. The reason for this could be that, in the nitrogen atmosphere, the released oxygen is not immediately removed from the surface as in the vacuum case, but reacts with iridium, so there might be some kind of an equilibrium for a while, allowing $\mathrm{IrO}_{2}$ to partially reconstruct instead of fully decomposing. With thin layers one also has to take into account the possible oxidizing impurities in the $\mathrm{N}_{2}$ stream, even though the already pure $\mathrm{N}_{2}(99.999 \%)$ was further purified before entering the furnace.

3.1.4. Annealing in forming gas. GIXRD measurements during the annealing of an $\mathrm{IrO}_{2}$ film in an atmosphere of forming gas $\left(5 \% \mathrm{H}_{2}\right.$ in $\left.\mathrm{N}_{2}\right)$ are shown in Fig. 10 and the refined unit-cell parameters in Fig. 11. The unit cell expands much faster before decomposition compared with annealing done in either a vacuum or nitrogen, indicating a highly unstable state. Decomposition to Ir occurs at $150^{\circ} \mathrm{C}$, which is $50^{\circ} \mathrm{C}$ lower than observed in a vacuum. Literature references on annealing in a

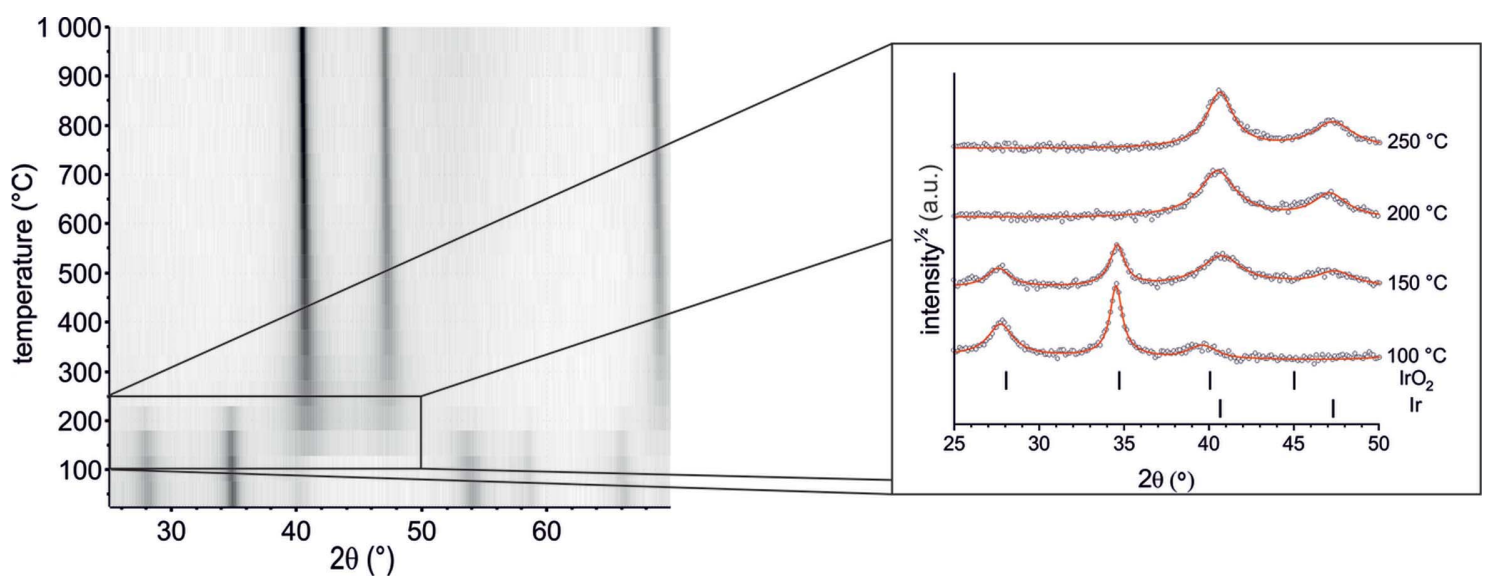

Figure 10

GIXRD measurements of an $\mathrm{IrO}_{2}$ film annealed in forming gas. The enlarged region on the right-hand side depicts the diffractograms at temperatures where the decomposition takes place; open circles are the measured data and red lines the Rietveld fits to the data. 
reducing atmosphere are rare. Chen et al. (1997) noticed that their sputtered $\mathrm{IrO}_{2}$ film reduced completely to Ir and peeled off at $450^{\circ} \mathrm{C}$, but they did not report results at other temperatures. Cross et al. (2002) studied the behaviour of $\mathrm{IrO}_{2}$ top electrodes by annealing $\mathrm{IrO}_{2} / \mathrm{PZT} / \mathrm{Pt} / \mathrm{Si}$ films (PZT is lead zirconium titanate) in $3 \% \mathrm{D}_{2} / \mathrm{N}_{2}$ or $3 \% \mathrm{H}_{2} / \mathrm{N}_{2}$ atmospheres at 6.0 mbar and found that, according to secondary ion mass spectroscopy, oxygen loss from the $\mathrm{IrO}_{2}$ film surface has already started after $10 \mathrm{~min}$ at $200^{\circ} \mathrm{C}$ and progresses more deeply when heated for a longer time. Auger electron spectroscopy was used to confirm that, after $15 \mathrm{~min}$, the film surface was reduced to metallic Ir and voids appeared on the surface. Metallic Ir was thought to be catalytically active in dissociating deuterium into $\mathrm{D}^{+}$ions which then diffused into the PZT.

3.1.5. Effect of annealing on crystallite size. The refined crystallite sizes in different atmospheres as a function of temperature are depicted in Fig. 12. On the basis of the results from the annealing in oxygen, the crystallites are elongated in the [001] direction and smaller in the [100] and [010] directions, suggesting cylindrical or ellipsoidal shapes. Similar crystallite size anisotropy was observed in the samples annealed in other atmospheres but, for the sake of clarity, only average values are plotted in Fig. 12(b). For the sample annealed in a nitrogen atmosphere, the crystallite size trend is similar to that of the oxygen-annealed sample up to $650^{\circ} \mathrm{C}$ where the decomposition takes place. Above that temperature there is a strong increase in the Ir crystallite size. Interestingly, the $\mathrm{IrO}_{2}$ sample annealed in a vacuum breaks into tiny Ir crystallites after decomposition at $200^{\circ} \mathrm{C}$, with a subsequent slow increase in the crystallite size up to $700^{\circ} \mathrm{C}$. Above that temperature the crystallite size increases at a rate close to that observed for the nitrogen-annealed sample. Since the trend in unit-cell parameters and crystallite sizes above $650^{\circ} \mathrm{C}$ is similar

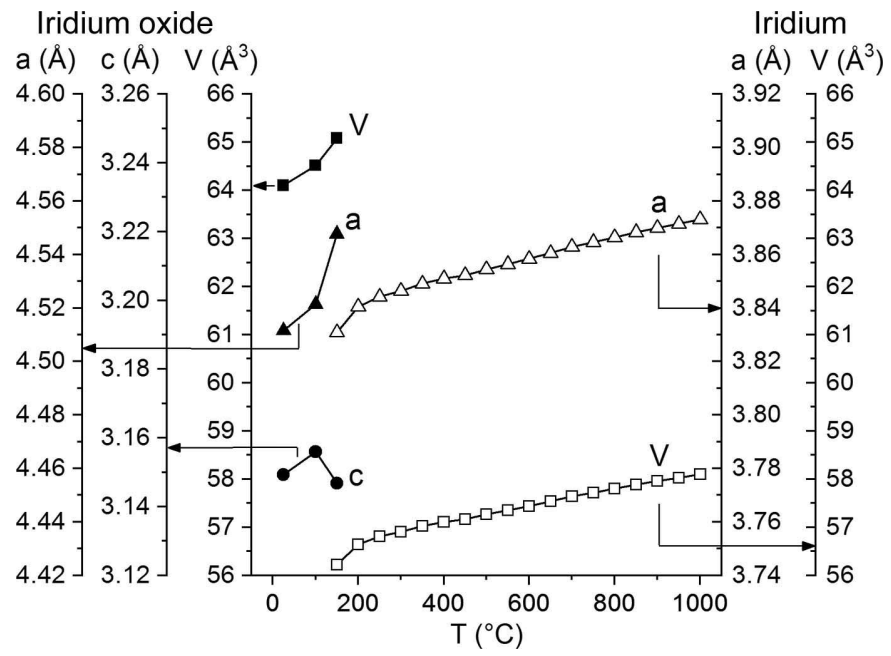

Figure 11

Rietveld-refined unit-cell parameters as a function of temperature for an $\mathrm{IrO}_{2}$ film annealed in forming gas. The three $y$ axes on the left-hand side are for the $a$ axis, $c$ axis and volume of the $\mathrm{IrO}_{2}$ unit cell, and the two $y$ axes on the right-hand side are for the $a$ axis and volume of the Ir unit cell. The horizontal arrows point to the axes at the positions of the literature values of the room-temperature unit-cell dimensions. for both nitrogen- and vacuum-annealed samples, the Ir atoms seem to be quite mobile to diffuse along the surface to form larger crystallites, and this is also observed in the FESEM images (Fig. 13). In the forming gas $\mathrm{IrO}_{2}$ breaks into small $\mathrm{Ir}$ crystallites at an even lower temperature than in a vacuum, but unlike in $\mathrm{N}_{2}$ or vacuum, the crystallite size of Ir increases above the decomposition temperature quite linearly.

Even though no macrostrain could be found, microstrain was analysed together with the crystallite size, and average values for the samples annealed in $\mathrm{O}_{2}$ and $\mathrm{N}_{2}$ are shown in Fig. 12(c). There seems to be a decreasing trend in both atmospheres until the onset of crystallite size increase. The onset temperature for the $\mathrm{IrO}_{2}$ crystallite size growth is around $400^{\circ} \mathrm{C}$, a slightly lower temperature than where the change in unit-cell parameters was observed (Fig. 2) or the surface roughness began to increase (Fig. 4). Although directly
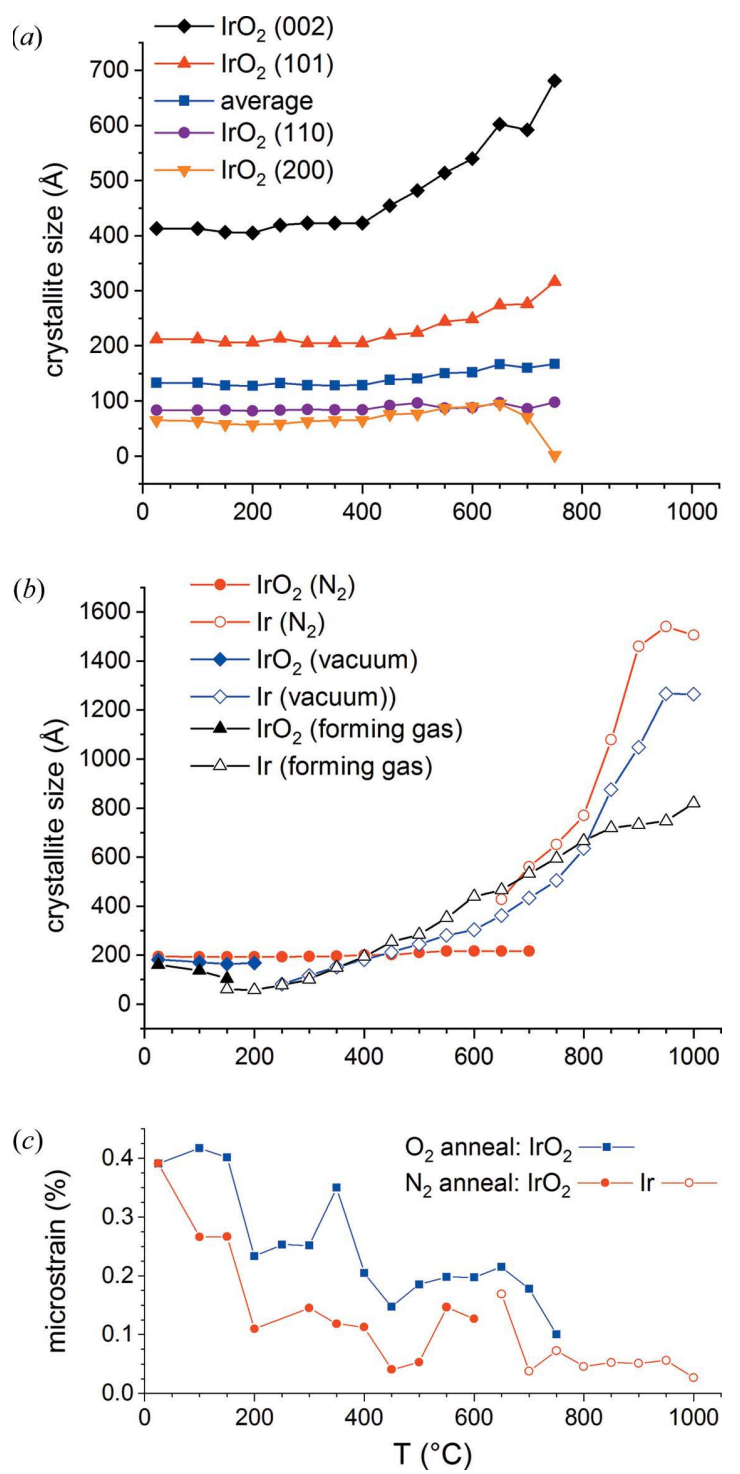

Figure 12

(a) The average crystallite size and the size calculated for different lattice planes as a function of annealing temperature in oxygen. $(b)$ The average crystallite sizes in nitrogen, vacuum and forming gas. (c) The average microstrain of the $\mathrm{IrO}_{2}$ film annealed in $\mathrm{O}_{2}$ and in $\mathrm{N}_{2}$. 


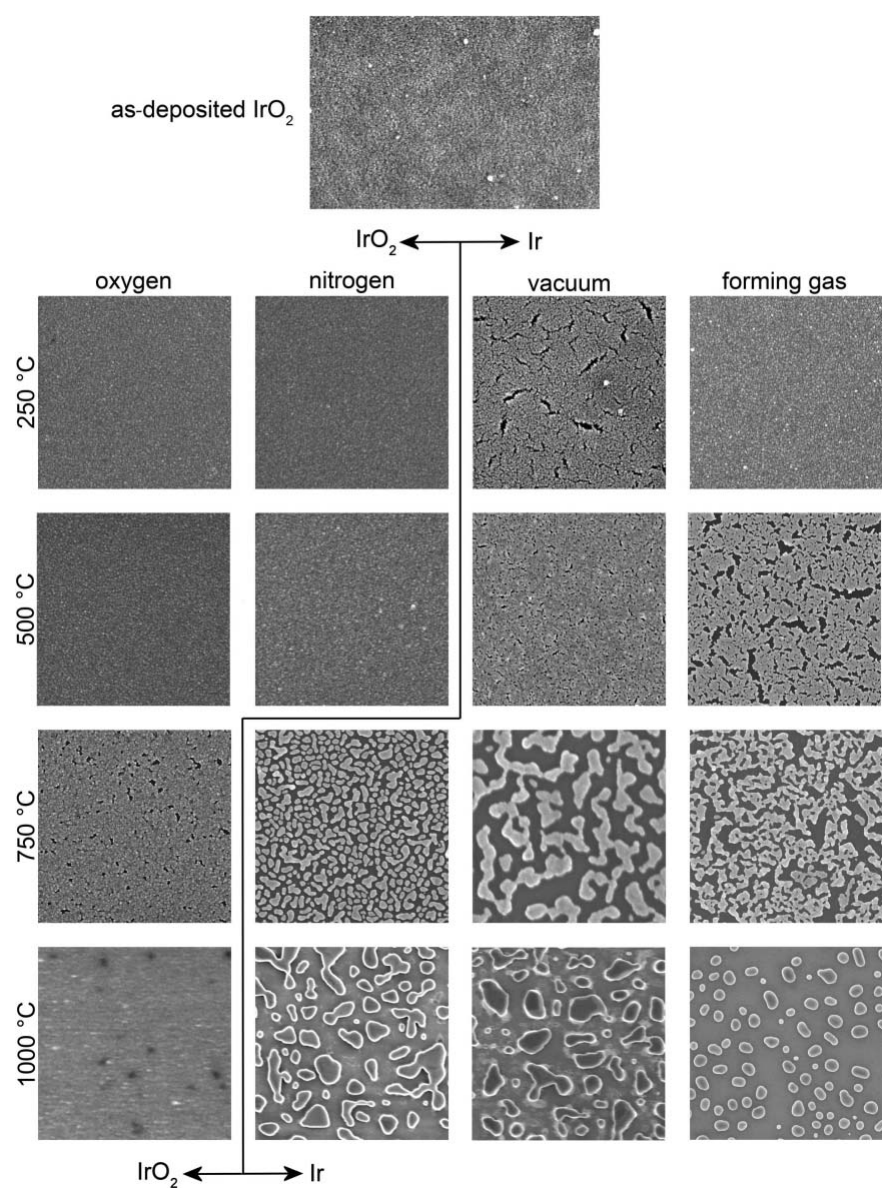

Figure 13

FESEM images of the $\mathrm{IrO}_{2}$ films heated to different temperatures in different atmospheres. The image sizes are $3 \times 2 \mu \mathrm{m}$ for the as-deposited film and $2 \times 2 \mu \mathrm{m}$ for the others.

comparable crystallite size growth data are not available, Hackwood et al. (1982) noticed that a sputtered amorphous $\mathrm{IrO}_{2}$ film crystallized at around $300^{\circ} \mathrm{C}$, and similar observations were reported for hydrothermal $\mathrm{IrO}_{x}$ by da Silva $e t$ al. (2017) between 300 and $400^{\circ} \mathrm{C}$ and for mesoporous $\mathrm{IrO}_{2}$ by Ortel et al. (2011) at $450^{\circ} \mathrm{C}$, although in the latter case the first signs of crystallization were observed at $300^{\circ} \mathrm{C}$ by transmission electron microscopy selected-area electron diffraction. In addition, Bernicke et al. (2015) noticed initial signs of sintering at $550^{\circ} \mathrm{C}$ in their porous films. All these data agree quite well with our crystallite growth temperature range.

3.1.6. Surface characterization. For surface characterization, the films were heated inside the Anton Paar oven in different atmospheres to selected temperatures and then cooled to room temperature. The temperatures were selected on the basis of the HTXRD measurements and similar heating rates were used. FESEM images of the annealed films are shown in Fig. 13. The film annealed in oxygen looks unchanged up to $500^{\circ} \mathrm{C}$, while the film annealed at $750^{\circ} \mathrm{C}$ is much rougher. These results agree well with the XRD (Fig. 2) and XRR (Fig. 4) results, since there is only a slight change in the crystallite size or in the film density, thickness and roughness up to $500^{\circ} \mathrm{C}$, while at higher temperatures the crystallite size and film roughness increase strongly. The r.m.s.

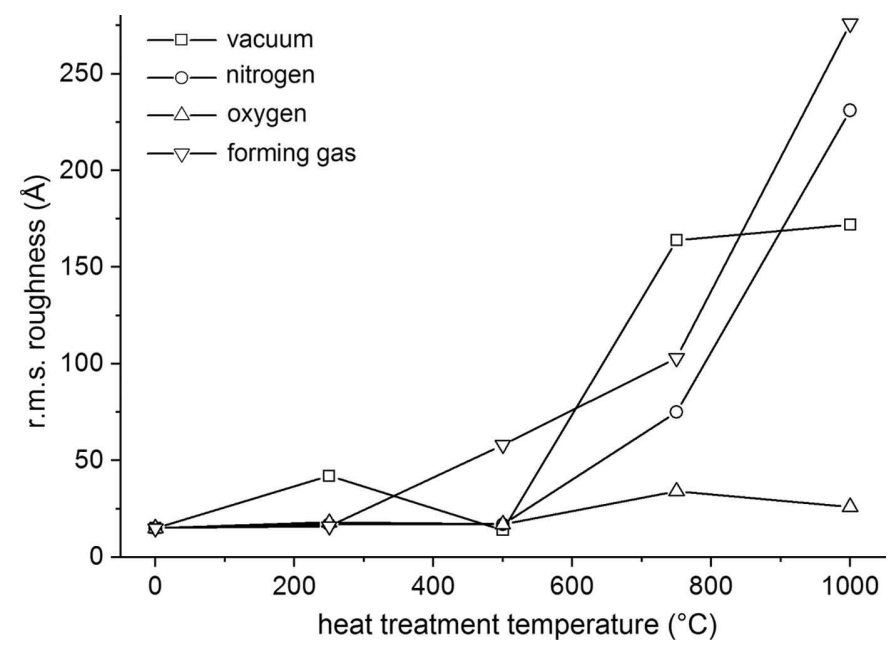

Figure 14

The r.m.s. roughnesses of the $\mathrm{IrO}_{2}$ films heated to different temperatures in different atmospheres as acquired from the AFM images.

roughness obtained by AFM is also consistent with the XRR and FESEM results, as seen in Fig. 14. For the film annealed at $1000^{\circ} \mathrm{C}$ in oxygen, both FESEM and AFM indicate that there is basically nothing left of $\mathrm{IrO}_{2}$ on the surface, which is reasonable since there was no diffraction signal at that temperature either.

On the basis of the HTXRD results, the nitrogen-annealed films should look comparable to the oxygen-annealed films up to $500^{\circ} \mathrm{C}$, and this is also evident from the FESEM images and AFM data. At $750^{\circ} \mathrm{C}$ there is only the Ir phase left in the nitrogen sample (Fig. 5), and this is observed as island formation in the FESEM and AFM images. At $1000^{\circ} \mathrm{C}$ the islands continue to grow. In a vacuum, the film begins to crack at $250^{\circ} \mathrm{C}$, which is consistent with the diffraction data (Fig. 8), and this may be the reason for the bump in the $250^{\circ} \mathrm{C} \mathrm{AFM}$ data as well (Fig. 14). There is no island formation, though, and the film surface is also quite smooth at $500^{\circ} \mathrm{C}$. This agrees well with the small crystallite size of the vacuum-annealed film [Fig. 12(b)]. The formation of an island network is observed at $750^{\circ} \mathrm{C}$ and separate islands at $1000^{\circ} \mathrm{C}$. In contrast to the nitrogen-annealed film, the island size seems to remain the same and there is only a small change in the r.m.s. roughness.

\section{Conclusions}

High-temperature X-ray diffraction and X-ray reflectivity measurements in oxygen, nitrogen, vacuum and forming gas were conducted on atomic layer deposited $\mathrm{IrO}_{2}$, and the surface morphology was further investigated using scanning electron microscopy and atomic force microscopy. Detailed analysis of the unit-cell parameters, phase composition and crystallinity was performed and the results were compared with the literature. The results of the present study give valuable information for researchers and industry by deepening the knowledge of the temperature and atmosphere stability of $\mathrm{IrO}_{2}$ films and the development of their microstructure upon annealing under different conditions. 
It was shown that in oxygen the $\mathrm{IrO}_{2}$ film is stable up to $800^{\circ} \mathrm{C}$, and at higher temperatures it evaporates as a volatile oxide. The stability was evident from the HTXRR data as well, since all the parameters remained essentially constant up to $500^{\circ} \mathrm{C}$, above which the film densified and the roughness started to increase until the destruction of the layer above $750^{\circ} \mathrm{C}$. The cause of the increasing roughness is clear from the crystallite sizes, which remain constant up to $400^{\circ} \mathrm{C}$ and then start to increase.

When annealed in forming gas, vacuum or nitrogen, $\mathrm{IrO}_{2}$ decomposed to Ir at 150,200 or $650^{\circ} \mathrm{C}$, respectively. The crystallite sizes of the resulting Ir films increased continuously above the reduction temperature while the film turned first into a network of islands and then, with increasing temperature, into separate islands. HTXRR was not well suited to studying the annealing in forming gas or vacuum due to the abrupt changes in the films at low temperatures. However, HTXRR gave useful information about the annealing in nitrogen as it showed how the film structure changed and developed density variations within the film even though there was no phase change or change in crystallinity. This sensitivity makes HTXRR a very attractive technique to observe even the smallest changes in thin films during annealing. It should be noted that in many thin-film device stacks the internal structure might be more important than the actual phasechange temperature. The behaviour of the interfaces during annealing is much better understood with in situ studies as they give more information about the development of film structure than numerous ex situ measurements.

\section{References}

Abbott, D. F., Lebedev, D., Waltar, K., Povia, M., Nachtegaal, M., Fabbri, E., Copéret, C. \& Schmidt, T. J. (2016). Chem. Mater. 28, 6591-6604.

Antolini, E. (2014). ACS Catal. 4, 1426-1440.

Bayer, G. \& Wiedemann, H. G. (1975). Thermochim. Acta, 11, 79-88.

Bernicke, M., Ortel, E., Reier, T., Bergmann, A., Ferreira de Araujo, J., Strasser, P. \& Kraehnert, R. (2015). ChemSusChem, 8, 19081915.

Bolzan, A. A., Fong, C., Kennedy, B. J. \& Howard, C. J. (1997). Acta Cryst. B53, 373-380.

Brewer, S. J., Deng, C. Z., Callaway, C. P., Paul, M. K., Fisher, K. J., Guerrier, J. E., Rudy, R. Q., Polcawich, R. G., Jones, J. L., Glaser, E. R., Cress, C. D. \& Bassiri-Gharb, N. (2016). J. Appl. Phys. 120, 024101.

Byun, K. \& Lee, W.-J. (2004). Jpn. J. Appl. Phys. 43, 2655-2660.

Carmo, M., Fritz, D. L., Mergel, J. \& Stolten, D. (2013). Int. J. Hydrogen Energy, 38, 4901-4934.

Cha, S. Y. \& Lee, H. C. (1999). Jpn. J. Appl. Phys. 38, L1128-L1130.

Chalamala, B. R., Wei, Y., Reuss, R. H., Aggarwal, S., Gnade, B. E., Ramesh, R., Bernhard, J. M., Sosa, E. D. \& Golden, D. E. (1999). Appl. Phys. Lett. 74, 1394-1396.

Chalamala, B. R., Wei, Y., Reuss, R. H., Aggarwal, S., Perusse, S. R., Gnade, B. E. \& Ramesh, R. (2000). J. Vac. Sci. Technol. B, 18, 1919-1922.

Chen, T.-S., Balu, V., Jiang, B., Kuah, S.-H., Lee, J. C., Chu, P., Jones, R. E., Zurcher, P., Taylor, D. J. \& Gillespie, S. (1997). Integr. Ferroelectr. 16, 191-198.
Choi, S., Cha, Y.-K., Seo, B.-S., Park, S., Park, J.-H., Shin, S., Seol, K. S., Park, J.-B., Jung, Y.-S., Park, Y., Park, Y., Yoo, I.-K. \& Choi, S.-H. (2007). J. Phys. D Appl. Phys. 40, 1426-1429.

Claus, C. (1860). J. Prakt. Chem. 80, 282-317.

Cogan, S. F. (2008). Annu. Rev. Biomed. Eng. 10, 275-309.

Cross, J. S., Horii, Y., Mizuta, N., Watanabe, S. \& Eshita, T. (2002). Jpn. J. Appl. Phys. 41, 698-701.

Danauskas, S. M., Li, D., Meron, M., Lin, B. \& Lee, K. Y. C. (2008). J. Appl. Cryst. 41, 1187-1193.

George, S. M. (2010). Chem. Rev. 110, 111-131.

Gong, Y., Wang, C., Shen, Q. \& Zhang, L. (2009). Mater. Chem. Phys. 116, 573-577.

Gong, Y., Wang, C., Shen, Q. \& Zhang, L. (2013). Appl. Surf. Sci. 285, 324-330.

Hackwood, S., Dayem, A. H. \& Beni, G. (1982). Phys. Rev. B, 26, 471-478.

Hämäläinen, J., Kemell, M., Munnik, F., Kreissig, U., Ritala, M. \& Leskelä, M. (2008). Chem. Mater. 20, 2903-2907.

Hämäläinen, J., Ritala, M. \& Leskelä, M. (2014). Chem. Mater. 26, 786-801.

Heikkilä, M. J., Hämäläinen, J., Ritala, M. \& Leskelä, M. (2011). Z. Kristallogr. Proc. 1, 209-214.

Hou, X., Takahashi, R., Yamamoto, T. \& Lippmaa, M. (2017). J. Cryst. Growth, 462, 24-28.

Hou, Y.-Y., Hu, J.-M., Liu, L., Zhang, J.-Q. \& Cao, C.-N. (2006). Electrochim. Acta, 51, 6258-6267.

Huang, W.-D., Cao, H., Deb, S., Chiao, M. \& Chiao, J. C. (2011). Sens. Actuators A Phys. 169, 1-11.

Jang, G.-W. \& Rajeshwar, K. (1987). J. Electrochem. Soc. 134, 18301835.

Jürgensen, L., Frank, M., Pyeon, M., Czympiel, L. \& Mathur, S. (2017). Organometallics, 36, 2331-2337.

Kim, H. W., Shim, S. H., Myung, J. H. \& Lee, C. (2008). Vacuum, 82, 1400-1403.

Kim, S.-W., Kwon, S.-H., Jeong, S.-J., Park, J.-S. \& Kang, S.-W. (2008). Electrochem. Solid-State Lett. 11, H303-H305.

Kim, S.-W., Kwon, S.-H., Kwak, D.-K. \& Kang, S.-W. (2008). J. Appl. Phys. 103, 023517.

Lee, A. van der (2000). Solid State Sci. 2, 257-278.

Lee, H.-S., Um, W.-S., Hwang, K.-T., Shin, H.-G., Kim, Y.-B. \& Auh, K.-H. (1999). J. Vac. Sci. Technol. A, 17, 2939-2943.

Leskelä, M., Niinistö, J. \& Ritala, M. (2014). Comprehensive Materials Processing, edited by S. Hashmi, G. F. Batalha, C. J. van Tyne \& B. Yilbas, Vol. 4, pp. 101-123. Amsterdam: Elsevier.

Liao, P. C., Chen, C. S., Ho, W. S., Huang, Y. S. \& Tiong, K. K. (1997). Thin Solid Films, 301, 7-11.

Liao, P. C., Huang, Y. S. \& Tiong, K. K. (2001). J. Alloys Compd. 317318, 98-102.

Lutterotti, L., Chateigner, D., Ferrari, S. \& Ricote, J. (2004). Thin Solid Films, 450, 34-41.

Mishra, D., Benitez, M. J., Petracic, O., Badini Confalonieri, G. A., Szary, P., Brüssing, F., Theis-Bröhl, K., Devishvili, A., Vorobiev, A., Konovalov, O., Paulus, M., Sternemann, C., Toperverg, B. P. \& Zabel, H. (2012). Nanotechnology, 23, 055707.

Nelson, A. (2006). J. Appl. Cryst. 39, 273-276.

O'Brien, B. \& Carroll, W. (2009). Acta Biomater. 5, 945-958.

Okuyama, M. (2016). Features, Principles and Development of Ferroelectric Gate Field-Effect Transistors, edited by B. Park, H. Ishiwara, M. Okuyama, S. Sakai \& S. Yoon, pp. 3-20. Dordrecht: Springer Netherlands.

Ortel, E., Reier, T., Strasser, P. \& Kraehnert, R. (2011). Chem. Mater. 23, 3201-3209.

Park, T. J., Jeong, D. S., Hwang, C. S., Park, M. S. \& Kang, N.-S. (2005). Thin Solid Films, 471, 236-242.

Patil, P. S., Chigare, P. S., Sadale, S. B., Seth, T., Amalnerkar, D. P. \& Kawar, R. K. (2003). Mater. Chem. Phys. 80, 667-675.

Pettersson, J., Ramsey, B. \& Harrison, D. (2006). J. Power Sources, 157, 28-34.

Peuckert, M. (1984). Surf. Sci. 144, 451-464. 
Pinnow, C. U., Kasko, I., Dehm, C., Jobst, B., Seibt, M. \& Geyer, U. (2001). J. Vac. Sci. Technol. B, 19, 1857-1865.

Pinnow, C. U., Kasko, I., Nagel, N., Poppa, S., Mikolajick, T., Dehm, C., Hösler, W., Bleyl, F., Jahnel, F., Seibt, M., Geyer, U. \& Samwer, K. (2002). J. Appl. Phys. 91, 9591-9597.

Popa, N. C. (1998). J. Appl. Cryst. 31, 176-180.

Potrepka, D. M., Rivas, M., Yu, H., Polcawich, R. G., Aindow, M. \& Fox, G. R. (2017). Thin Solid Films, 638, 127-137.

Rao, K. V. K. \& Iyengar, L. (1969). Curr. Sci. 38, 304-305.

Rasten, E., Hagen, G. \& Tunold, R. (2003). Electrochim. Acta, 48, 3945-3952.

Ritala, M. \& Niinistö, J. (2009). ECS Trans. 25(8), 641-652.

Rumble, J. R. (2018). Editor. CRC Handbook of Chemistry and Physics, Internet Version 2018, 99th ed., Section 4. Boca Raton: CRC Press/Taylor \& Francis.

Sanjinés, R., Aruchamy, A. \& Lévy, F. (1989). J. Electrochem. Soc. 136, 1740-1743.

Shim, J. H., Lee, Y., Kang, M., Lee, J., Baik, J. M., Lee, Y., Lee, C. \& Kim, M. H. (2012). Anal. Chem. 84, 3827-3832.
Silva, G. C. da, Perini, N. \& Ticianelli, E. A. (2017). Appl. Catal. Environ. 218, 287-297.

Sun, Y., Frenkel, A. I., Isseroff, R., Shonbrun, C., Forman, M., Shin, K., Koga, T., White, H., Zhang, L., Zhu, Y., Rafailovich, M. H. \& Sokolov, J. C. (2006). Langmuir, 22, 807-816.

Tomczyk, M., Stroppa, D. G., Reaney, I. M. \& Vilarinho, P. M. (2017). Phys. Chem. Chem. Phys. 19, 14337-14344.

Trasatti, S. (2000). Electrochim. Acta, 45, 2377-2385.

Vignaud, G. \& Gibaud, A. (2019). J. Appl. Cryst. 52, 201-213.

Wang, C., Gong, Y., Shen, Q. \& Zhang, L. (2006). Appl. Surf. Sci. 253, 2911-2914.

Wen, R.-T., Niklasson, G. A. \& Granqvist, C. G. (2014). Solar Energy Mater. Solar Cells, 120, 151-156.

Wöhler, L. \& Witzmann, W. (1908). Z. Anorg. Chem. 57, 323-352.

Yagi, M., Tomita, E. \& Kuwabara, T. (2005). J. Electroanal. Chem. 579, 83-88.

Zhang, F., Barrowcliff, R. \& Hsu, S. T. (2005). Proceedings of the 2005 International Conference on MEMS, Nano and Smart Systems, pp. 418-420. IEEE Computer Society. 